\title{
A Broadband U-slot Loaded Cylindrical Disk Microstrip Patch Antenna
}

\author{
Shubhanka Agrawal \\ Digital Communication \\ (M.Tech. Student) \\ B.I.S.T., Bhopal \\ (M.P.), India
}

\author{
Dhruv Singh Thakur \\ E.C.E. Department \\ B.I.S.T., Bhopal \\ (M.P.) India
}

\author{
K. K. Nayak (H.O.D.) \\ E.C.E Department \\ B.I.S.T., Bhopal \\ (M.P.), India
}

\begin{abstract}
In this paper first we design $\mathrm{V}$-shaped slot loaded and cylindrical slot loaded microstrip patch antenna fed by a microstrip line $(50 \Omega)$ and analyze its performance. The proposed antenna is designed by using HFSS simulation tool. Feeding is done by using microstrip feed line. After designing antenna we see the effect of variation in the dielectric material of substrate, and length of cylindrical slot and ground plane variation on antenna bandwidth is analyzed. This antenna design gives impedance bandwidth of $10 \mathrm{GHz}$ operating over a frequency range of 3.5 to $14.1 \mathrm{GHz}$ with VSWR $<2$. These characteristics make the designed antenna suitable for various ultra wideband applications.
\end{abstract}

\section{Keywords}

Microstrip Antenna, Dielectric Constant, Cylindrical Slot, Ultra Wideband Antenna.

\section{INTRODUCTION}

Consider the term "ultra wideband" (UWB) as a relatively new term to describe a technology, which had been known since the early 1960's. The old definition was referring to "carrier-free", "baseband", or "impulse" technology. The fundamental concept is to develop, transmit and receive an extremely short duration burst of radio frequency (RF) energy, like a short pulse. The pulse typically has duration of a few tens of picoseconds to a few nanoseconds. These pulses represent one to only a few cycles of an RF carrier wave; therefore, as for resultant waveforms, extremely broadband signals can be achieved. Often it is difficult to determine the actual RF center frequency for an extremely short pulse; thus, the term "carrier-free" comes in. The amount of power transmitted is a few milliwatts, which, when coupled with the spectral spread, produces very low spectral power densities. The Federal Communication Commission (FCC) specifies that between 3.1 and $10.6 \mathrm{GHz}$, the emission limits should be less than $-41.3 \mathrm{dBm} / \mathrm{MHz}$, or $75 \mathrm{nW} / \mathrm{MHz}$. The total power between these limits is a mere $0.5 \mathrm{~mW}$.

The entire paper has been partitioned into five parts. In II, literature reviews for microstrip patch antenna have been discussed. In III, antenna design for double U-slot rectangle patch antenna hardware structure is discussed. In IV, result and discussion has beendiscussed. In $\mathrm{V}$, conclusions and future scope of the paper work has been presented.

\section{LITERATURE REVIEW}

N. P. Yadavet al., [1], proposed "A Broadband U-slot loaded circular disk patch Antenna". In this paper, size of the substrate is $70 \mathrm{~mm} * 60 \mathrm{~mm}$ and use RT/Duriod 5870 substrate with dielectric constant $\epsilon_{r}=2.2$ and thickness between ground and fed patch $(\mathrm{h})=1.575 \mathrm{~mm}$. Here, we use radius of fed disk path $(\mathrm{R})=10.65 \mathrm{~mm}$ and length of U-slot $\left(L_{s}\right)=11.0 \mathrm{~mm}$. In this paper, patch antenna is simulated on IE3D software and also experimentally. Experimental results shows return loss is less than $-10 \mathrm{~dB}$ for the range $3.8 \mathrm{GHz}$ to $12 \mathrm{GHz}$. Its $\mathrm{E}$ and $\mathrm{H}$-plane patterns are stable over the UWB frequency range.

Mulgi.et al., [2], studied about the effect slot loading in a rectangular microstrip antennas. In this paper, first conventional microstrip antenna is designed which operates at frequency of $4 \mathrm{GHz}$. Then three slots loaded at different positions in microstrip antennas. Triple band operation can be achieved by keeping the distance between two slots 0.2 and $0.3 \mathrm{~cm}$. Therefore, due to slot loading, we get multi resonant peaks achieved and bandwidth also increases by an amount of $15.05 \%$.

Dubey.et al., [3], proposed compact rectangular L-shaped slot microstrip antenna for UWB applications.A ultra wideband (UWB) microstrip antenna with half U-slot is analyzed using equivalent circuit model based on modal expansion cavity model. The effect of slot length, slot width and distance between feed point allocation and slot are analyzed to obtain the optimum for UWB operation of the antenna. Antenna shows a lower frequency band $3.262 \mathrm{GHz}$ to $5.389 \mathrm{GHz}$ (22.73) and upper operational frequency band $5.869 \mathrm{GHz}$ to $9.033 \mathrm{GHz}(47.69 \%)$. Results of the proposed antenna are in good agreement with the simulated results.

\section{ANTENNA DESIGN}

In this paper, $\mathrm{V}$ shape and cylindrical slot loaded microstrip patch antenna is designed by using ANSOFT HFSS (High Frequency Structural Simulator)[4]. Method of finite element solver is used. First of all we specify, following three input parameters which is decided by the designer according to specifications

$\varepsilon_{r}=$ Dielectric constant of the substrate

$h=$ Thickness of the substrate

$f_{0}=$ Resonant frequency

After deciding the values of these parameters the value of width and length of microstrip antenna will be determined. In order to get ultra wide bandwidth in microstrip antenna feeding point is $2.5 \mathrm{~mm}$ away from the symmetrical position of radiator. For an efficient radiator, a practical width that leads to good radiation efficiencies is 


$$
W=\frac{c}{2 f_{0} \sqrt{\frac{\varepsilon_{r}+1}{2}}}
$$

Figure 1 and Figure 2 shows the design of different types of microstrip patch antenna i.e. V Shape slot microstrip patch antenna and cylindrical slot loaded microstrip patch antenna respectively.

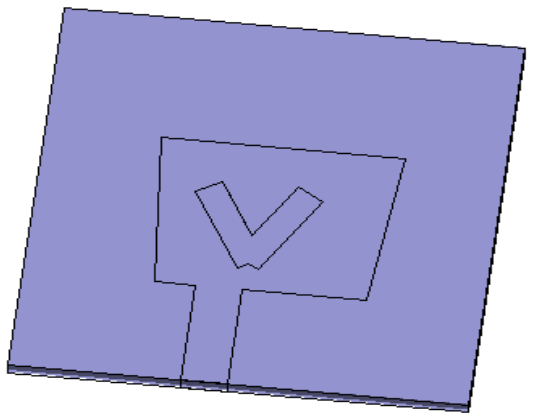

Figure 1: Design of V Shape Slot Loaded Microstrip patch Antenna

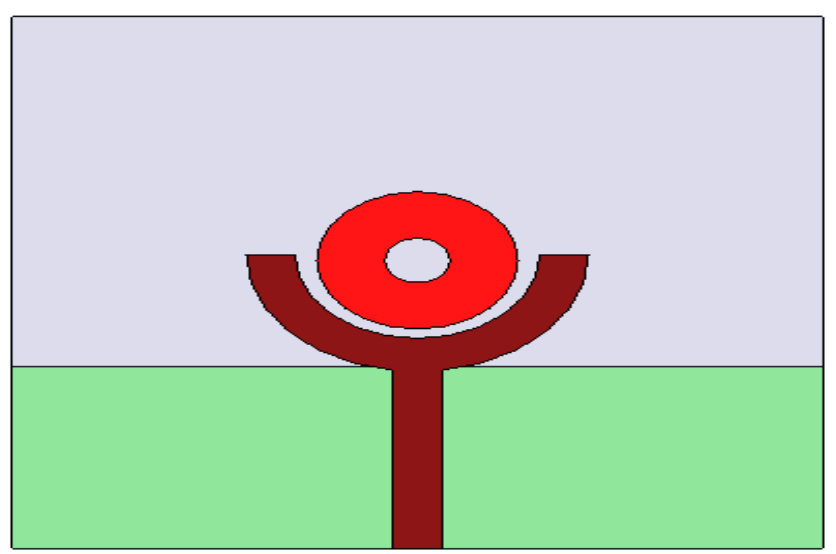

Figure 2: Design of Cylindrical Slot Loaded Microstrip Patch Antenna

The actual length of the patch can now be determined as follow

$$
L_{\text {actual }}=L_{\text {eff }}-\Delta L
$$

Where,

$L_{e f f}=$ Effective length of the patch.

$\Delta L=$ Extended electrical length

Effective length of the patch is simply given by

$L_{e f f}=\frac{c}{2 f_{0} \sqrt{\varepsilon_{\text {reff }}}}$

Here $\varepsilon_{\text {reff }}$ Effective dielectric constant. For low frequencies the effective dielectric constant is essentially constant.

\section{RESULTS AND DISCUSSION}

Both designs are simulated on HFSS software. In HFSS, V shape, cylindrical patch and partial ground plane are made up of PEC (Perfect Electrical Conductor) and air or vacuum can be used for the radiation box. Return loss gives us an amount of power being reflected by the input port. For UWB antenna, return loss below $-10 \mathrm{~dB}$ is considered to be quite efficient. For this antenna design return loss is less than $-10 \mathrm{~dB}$ in frequency range $5.11-9.34 \mathrm{GHz}$.

Figure 3 and Figure 4 shows return loss v/s frequency curve of $\mathrm{V}$ shape antenna for a particular length of ground plane respectively.

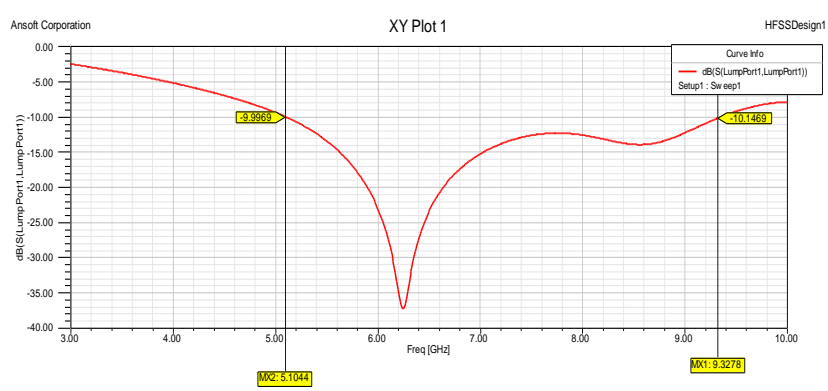

Figure 3: Variation of Return loss (S11) vs. Frequency of V Shape

Figure 4 Shows Voltage Standing Wave Ratio (VSWR) plot vs. Frequency in GHz. VSWR is simply the ratio of peak amplitude of standing wave ratio. VSWR below 2 is considered well for an antenna. For this design, VSWR is less than 2 from $5.11-9.34 \mathrm{GHz}$.

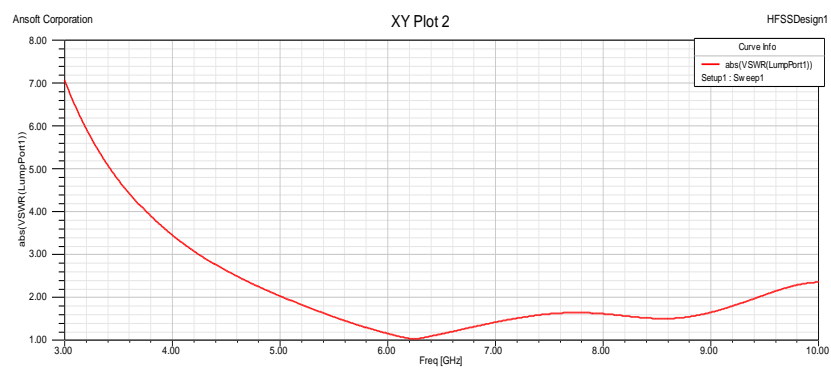

Figure 4: VSWR v/s frequency curve of V Shape

Figure 5 return loss v/s frequency curve of cylindrical slot antenna at particular length of ground plane respectively i.e. from $3.11-6.39 \mathrm{GHz}$

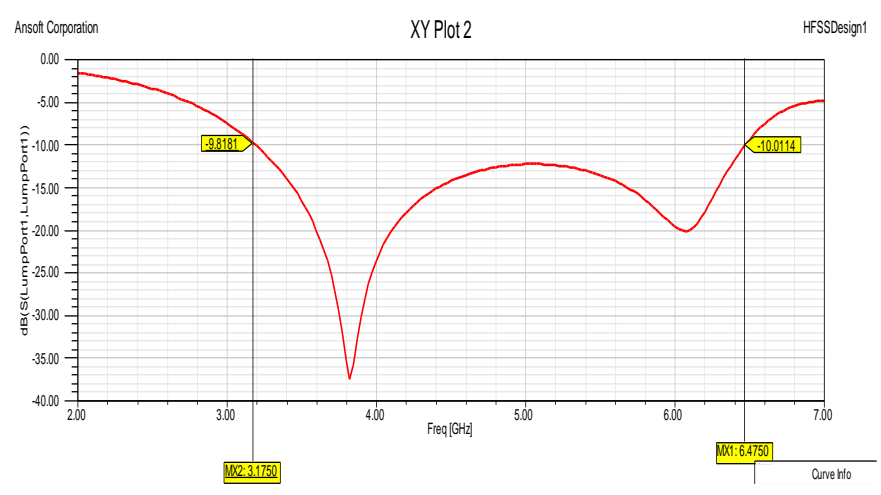

Figure 5: Return loss v/s frequency curve w.r.t length of Cylindrical slot 
Figure 6 shows the VSWR v/s frequency curve for varying length of Cylindrical Shape . At all frequencies the VSWR remain below 2 which makes the respective system quite efficient.

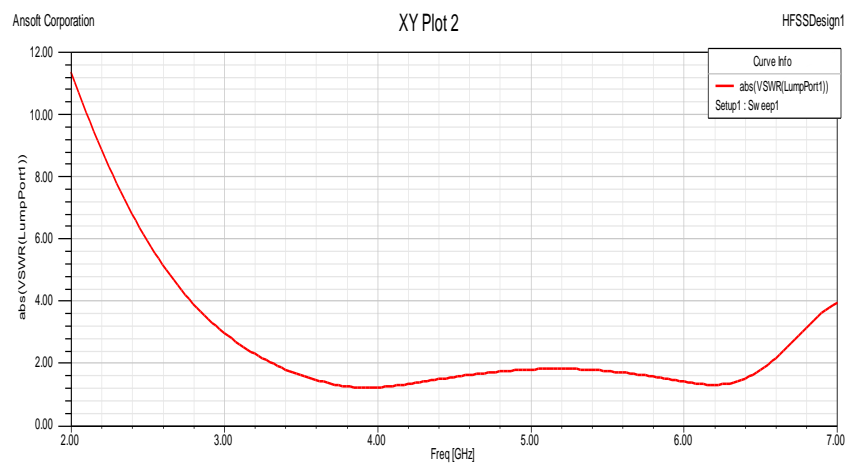

Figure 6: VSWR v/s frequency curve for varying length of Cylindrical

From the figure 7 and table 1 it is clear that optimum bandwidth is achieved when length of ground plane is 16.4 $\mathrm{mm}$.

Table 1: Bandwidth at Different Length of Ground Plane

\begin{tabular}{|c|c|c|c|}
\hline $\begin{array}{c}\text { Length of } \\
\text { ground } \\
\text { plane }\end{array}$ & $\begin{array}{c}\text { Frequency } \\
\text { Range }\end{array}$ & $\begin{array}{c}\text { Bandwidth } \\
(\mathbf{G H z})\end{array}$ & $\begin{array}{c}\text { Fractional } \\
\text { Bandwidth } \\
(\%)\end{array}$ \\
\hline $16.4 \mathrm{~mm}$ & $3.14-6.17$ & 3.03 & 70.8 \\
\hline $17.4 \mathrm{~mm}$ & $3.4-6.5$ & 3.1 & 64.58 \\
\hline $18.4 \mathrm{~mm}$ & $5.8-6.5$ & 0.7 & 11.38 \\
\hline $19.4 \mathrm{~mm}$ & $6-6.6$ & 0.6 & 9.5 \\
\hline
\end{tabular}

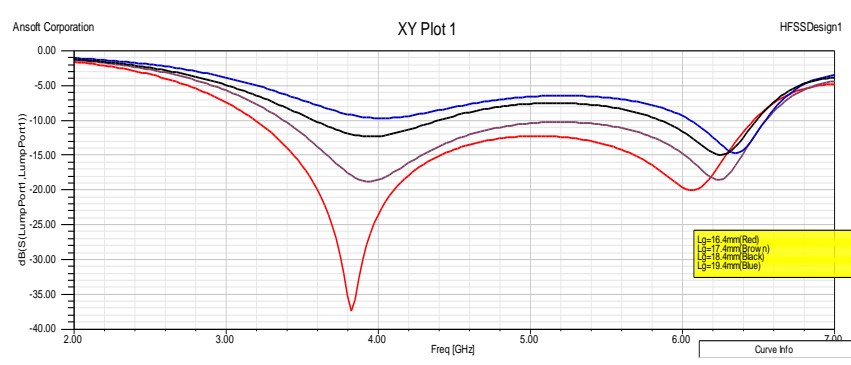

Figure 7: Return loss v/s frequency curve for varying length of ground plane

Figure 8 shows return loss v/s frequency curve for varying dielectric constant in GHz. Dielectric constant is simply a quantity measuring the ability of a substance to store electrical energy in an electric field. From the figure 8 and table 2 it is clear that optimum bandwidth is achieved when dielectric constant is $4.4 \mathrm{~mm}$.
Table 2: Bandwidth at Different Dielectric Constant

\begin{tabular}{|c|c|c|c|}
\hline $\begin{array}{c}\text { Dielectric } \\
\text { Constant }\end{array}$ & $\begin{array}{c}\text { Frequency } \\
\text { Range }\end{array}$ & $\begin{array}{c}\text { Bandwidth } \\
(\mathbf{G H z})\end{array}$ & $\begin{array}{c}\text { Fractional } \\
\text { Bandwidth } \\
(\boldsymbol{\%})\end{array}$ \\
\hline 2.2 & $4-7.5$ & 3.5 & 60.86 \\
\hline 4.4 & $3.1-6.5$ & 3.4 & 70.84 \\
\hline 4.8 & $3.2-6.4$ & 3.2 & 66.67 \\
\hline 5.5 & $3-6$ & 3 & 65.6 \\
\hline
\end{tabular}

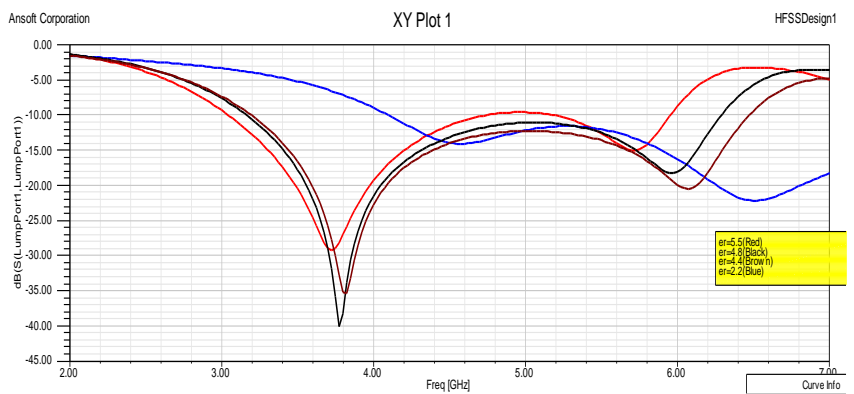

Figure 8: Return loss v/s frequency curve for varying Dielectric Constant

Figure 9 and Figure 10 shows 2D E-plane radiation pattern of $\mathrm{V}$-Shaped slot loaded antenna at different frequencies with in the band 4.1-14.1 GHz.
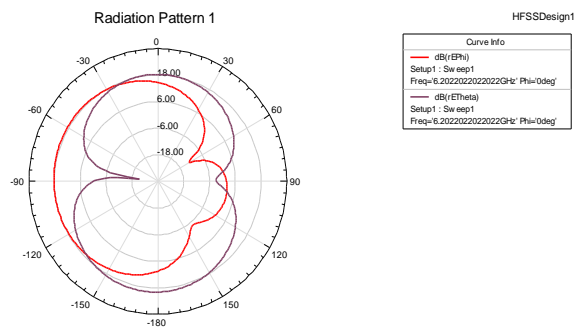

Figure 9: V Shape 2D E plane Radiation Pattern at $6 \mathrm{GHz}$

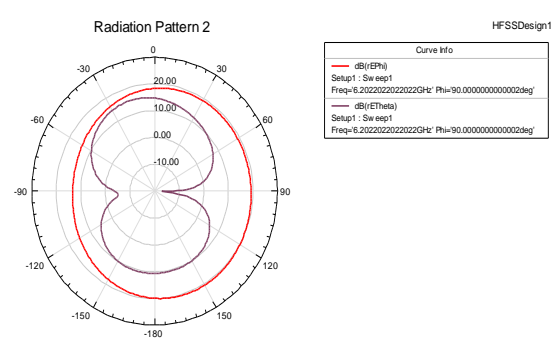

Figure 10: V Shape 2D H Plane Radiation Pattern at 6 GHz

Figure 11 and Figure 12 shows 2D E-plane and Figure 13 and Figure 14 shows H-planeradiation pattern of Cylindrical slot antenna respectively at different frequencies i.e. $3.9 \mathrm{GHz}$ and $6.2 \mathrm{GHz}$ with in the band of 4.1-14.1 GHz. 

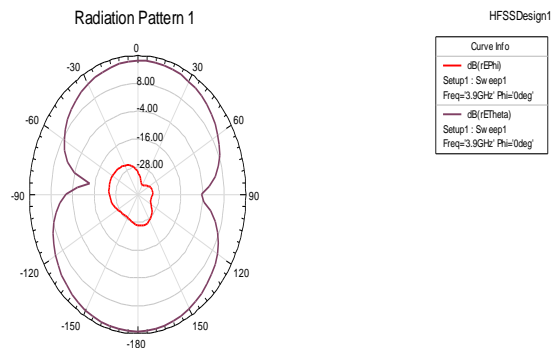

Figure 11: Cylindrical 2D E-Plane Radiation Pattern at $3.9 \mathrm{GHz}$ Ansot Coporation
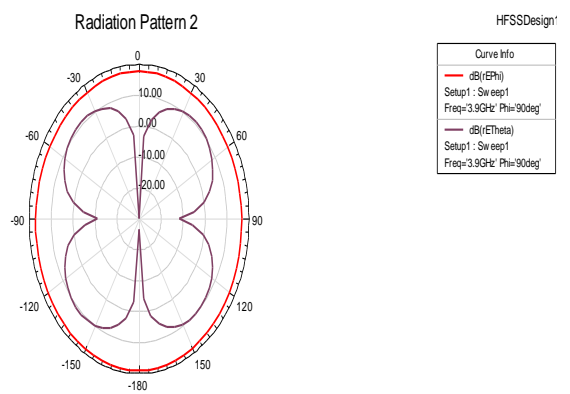

Figure 12: Cylindrical 2D H-Plane Radiation Pattern at 3.9 GHz Arsol coporation
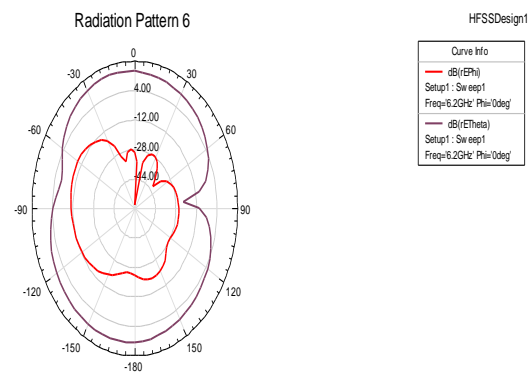

Figure 13: Cylindrical 2D E-Plane Radiation Pattern at $6.2 \mathrm{GHz}$
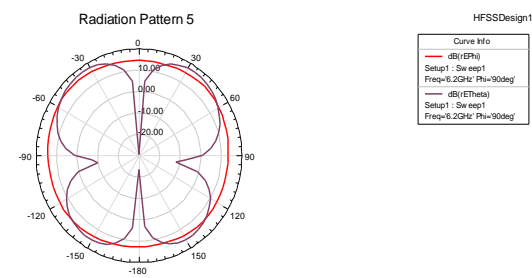

Figure 14: Cylindrical 2D H-Plane Radiation Pattern at $6.2 \mathrm{GHz}$

Figure 12 and Figure 13 shows 3D radiation pattern at different frequencies within the band 4.1-14.1 GHz
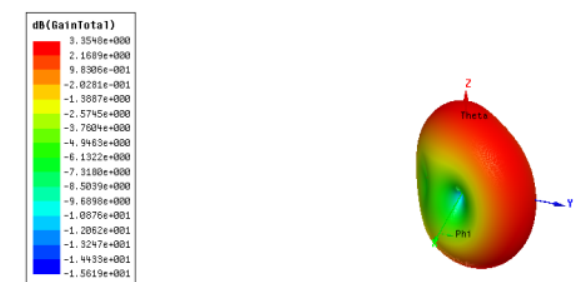

Figure 15: V Shape 3D Radiation Pattern at $6 \mathrm{GHz}$
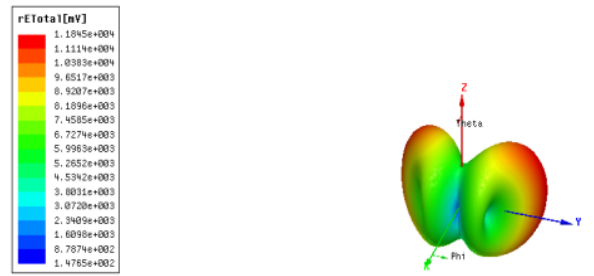

Figure 16: Cylindrical Shape 3D Radiation Pattern at 6.2 GHz

\section{CONCLUSION}

It is observed that V Shaped slot and Cylindrical Shape slot microstrip antenna provided optimum bandwidth when length of partial ground plane is $16.4 \mathrm{~mm}(3.14-6.17 \mathrm{GHz}$ i.e. 3.03 $\mathrm{GHz}$ ), and feeding position is $3 \mathrm{~mm}$ from symmetrical position.Finally, we saw the effect of varying dielectric material on bandwidth and got optimum bandwidth by using FR-4 epoxy substrate In the end, we design an antenna having ground plane length $16.4 \mathrm{~mm}$, U-slot width $2.5 \mathrm{~mm}$, feeding position $3 \mathrm{~mm}$ from symmetrical position, substrate material is FR-4 epoxy, then we get bandwidth $(\mathrm{S} 11<-10 \mathrm{~dB})$ 3.5 GHz (3.1-6.5 GHz). The proposed design of the antenna can be used for a variety of UWB applications including high speed data transfers, wireless connectivity between UWBenabled devices and a variety of medical applications.

\section{REFERENCES}

[1] N. P. Yadav, Anurag Mishra, P. Singh, J. A. Ansari and B. R. Vishvakarma, "A BroadbandU-slot loaded circular disk patch Antenna",2009 International Conference on Emerging Trends in Electronic and Photonic Devices \& Systems (ELECTRO-2009).

[2] Tavel, Mulgi, Shanna V K,Bhatnager D , Saini J . S "Compact dual frequency wide band circular patch antenna with V-slot," in Proc. of IEEE International symposium on Antenna and propoagation and VSNC/URSI NationalRadio Science Meeting, VSA, 2010.

[3] S. W. Dubey, S. M. Park, N. Kim, S. W. Park, and S. Y.Rhee, "Design and SAR Measurement of the Trapezoidal Shape Antenna," Progress in Electromagnetics Research C, vol. 26, pp. 127- 136, 2008.

[4] J.A. Ansari, Anurag Mishra, Ashish Singh, ,"Analysis ofUltra-Wideband Patch Antenna for S,C \& X BandApplications", International Conference on computer \&Communication Technology(ICCCT)-2011.

[5] Trapezoida dielectric resonator", Progress in Electromagnetics Research C, Vol. 16, 127-136, 2010.

[6] Claudia Veni and FilibertoBilotti, "Parametric Analysis of Slot-Loaded Trapezoidal Patch Antenna," IEEE Trans. on Antenna and Propagation, vol.50, no.9, September 2002.

[7] YogeshBhomia, Ashok Kajila\& Dinesh Yadav, "Vslotted triangular microstrip patch antenna," International Journal of Electronics engineering, 2(1), pp.21-23, 2010.

[8] M.Ali, R.Dougal, G.Yang and H.S Hwang, "Wide band circularly polarized microstrip patch antenna for wireless LAN applications," Progress in Electromagnetics Research B, Vol. 26, 27-36, 2009. 
[9] Xu-bao Sun, Mao-yong Cao, jian-junHao, “ A rectangular slot antenna with improved bandwidth," International Journal of electronics and communication(AEU),2011.

[10] Guillanton, E., Dauvignac, J. Y., Pichot, C., \&Cashman, J. (1998). A new design tapered slot antenna for ultrawideband applications. Microwave and Optical Technology Letters, 19(4), 286-289.

[11] Qu, S. W., Ruan, C., \& Wang, B. Z. "Bandwidth enhancement of wide-slot antenna fed by CPW and microstrip line", IEEE Antennas and Wireless Propagation Letters, 5(1), 15-17 (2006).

[12] Latif, S. I., Shafai, L., \& Sharma, S. K. "Bandwidth enhancement and size reduction of microstrip slot antenna”, IEEE Transactions on Antennas and Propagation, 53(3), 994-1003 (2005).

[13] J.A. Ansari, Anurag Mishra, Ashish Singh "Ultra Wideband Coplanar Microstrip Patch Antenna for Wireless Applications", Wireless PersCommun (2013)69:1365-1378 DOI 10.1007/s 11277-012-0638-y

[14] Anand Sharma and Rajesh Kumar Vishwakarma, "Microstrip Antenna WithSwastik Slot For UWB Applications"2014 IEEE Students' Conference on Electrical, Electronics and Computer Science. 